\title{
TECNOLOGIA DA INFORMAÇÃO NA GESTÃO DE CIDADES: UM ESTUDO DE CASO DE IMPLANTAÇÃO DE ERP EM UM MUNICÍPIO PAULISTA
}

\section{INFORMATION TECHNOLOGY IN THE MUNICIPAL MANAGEMENT: A CASE STUDY OF ERP IMPLEMENTATION IN A SÃO PAULO STATE TOWN}

\author{
José Alexandre Moreno ${ }^{1}$;osé Alcides Gobbo Junior ${ }^{2}$; Vagner Cavenaghi ${ }^{3}$ \\ ${ }^{1}$ Faculdade de Engenharia de Bauru - FEB/UNESP - Bauru - Brasil jamoreno@,feb.unesp.br \\ ${ }^{2}$ Faculdade de Engenharia de Bauru - FEB/UNESP - Bauru - Brasil gobbo@,feb.unesp.br \\ ${ }^{3}$ Faculdade de Engenharia de Bauru - FEB/UNESP - Bauru - Brasil vagnerc@,feb.unesp.br
}

\begin{abstract}
Resumo
A dinâmica de crescimento e desenvolvimento dos municípios, principalmente a partir de 2000, trouxe novas atribuições às administrações municipais, pois estas passaram a assumir responsabilidades que antes eram dos governos estadual ou federal. Esta nova realidade trouxe a necessidade da utilização de modelos de gestão que permitissem melhorar a arrecadação própria e a forma de gastar recursos. Esse artigo tem como objetivo estudar como a utilização de sistemas Enterprise Resource Planning (ERP) podem contribuir na gestão das cidades. Para tanto, é apresentado um estudo de caso de uma experiência bem sucedida de implantação de ERP na administração pública municipal.
\end{abstract}

Palavras-chave: ERP, gestão municipal, governança.

\section{Introdução}

As cidades brasileiras sofrem simultaneamente os problemas dos países desenvolvidos e daqueles em desenvolvimento. Isso é mais perceptível no caso das metrópoles, que enfrentam problemas ambientais das cidades modernas combinados com os decorrentes do subdesenvolvimento. A industrialização acarreta a poluição do ar e da água, gera o descompasso entre o crescimento das cidades e suas infra-estruturas básicas, criando problemas referentes às condições de vida e de consumo das populações humanas e à própria base da reprodução da esfera produtiva (SANTOS et. al., 2003).

Não resta dúvida de que a democracia evoluiu bastante nestes últimos anos, tendo como um dos principais avanços o processo de descentralização que abriu caminho para políticas inovadoras 
nos municípios brasileiros, tanto no plano da participação, quanto na área social e até mesmo ambiental. Assim, analisando essa nova concepção de gestão de cidades e de desenvolvimento integrado dos municípios - econômico, social e ambiental - surgem as parcerias que aproximam, cada vez mais, o poder público da sociedade. Dessa forma têm surgido inúmeros projetos que visam dar maior transparência e objetividade na administração dos recursos públicos, que cada vez são mais escassos.

Ao mesmo tempo, as necessidades do município e seus moradores tornam-se maiores e mais específicas a cada dia, o que resulta em demandas antes não existentes no contexto da administração pública municipal. A partir de 2000 os municípios passaram a assumir várias funções que originalmente eram do governo estadual e/ou federal, como o ensino básico e fundamental, que passou a ser de responsabilidade dos municípios. Por outro lado, a própria dinâmica de crescimento e desenvolvimento dos municípios trouxe novas atribuições à administração municipal.

A partir da promulgação da Lei de Responsabilidade Fiscal - LRF (NASCIMENTO; DELBUS, 2007), todos os administradores públicos se viram obrigados a utilizar os recursos de forma mais ordenada e de modo que atendesse o previsto na citada lei. A LRF passou a exigir dos municípios maior transparência na administração, como também a necessidade de programas de gestão específicos que demonstrassem a aplicação adequada e eficiente dos recursos disponibilizados. Um exemplo é a exigência de programa de gerenciamento e controle de perdas na produção e distribuição de água, sem o qual não é possível obter recursos financiados e/ou a fundo perdido oriundos do governo federal. A LRF impõe, entre outros itens, limites para as despesas com pessoal ativo e inativo, tanto da administração direta como da indireta.

Por outro lado, a sociedade tem exigido cada vez mais dos administradores em termos de obras, serviços, saúde e educação, e os recursos disponíveis não são suficientes para atender às demandas. Juntando-se a este cenário, no ano de 2006 a maioria dos municípios brasileiros com mais de 20.000 habitantes elaborou e promulgou o Plano Diretor do Município, instrumento de gestão estabelecido no Estatuto da Cidade. (BRASIL, 2001)

Essa nova realidade implica em quebras de paradigmas e adoção de métodos de gestão que possibilitem aos administradores públicos planejar suas ações e utilizar os recursos públicos de modo adequado à legislação e às necessidades da população.

A premissa é que, sem um sistema computacional de coleta e tratamento das informações, não é possível obter êxito na intenção de melhorar a gestão municipal. Os sistemas de Enterprise Resource Planning (ERP), são uma das ferramentas computacionais que permitem a obtenção de dados e informações em tempo real, além de possibilitar a integração entre as várias áreas da organização. Um sistema ERP tem a pretensão de suportar todas as necessidades de informação para a tomada de decisão gerencial de um empreendimento como um todo. É basicamente composto 
de módulos que atendem as necessidades de informação para apoio à tomada de decisão de setores que vão além da manufatura, como distribuição física, custos, recebimento fiscal, faturamento, recursos humanos, finanças e contabilidade, dentre outros. Todos esses setores estão integrados entre si, a partir de uma base de dados única e não redundante.

Esse artigo propõe a seguinte questão de pesquisa: "Como a implantação de um sistema ERP pode contribuir às operações realizadas pela administração pública municipal e permitir a tomada de decisões importantes para o município?".

Nesse contexto, esse artigo apresenta um levantamento bibliográfico sobre o ERP. É analisado também, um estudo de caso que demonstra a contribuição da tecnologia da informação na gestão de cidades, apontando as dificuldades inerentes a um processo de implantação, bem como os resultados que podem ser obtidos em benefício da administração pública e da própria população envolvida. Para tanto, foi usado como base para os estudos as ações desenvolvidas pela Prefeitura Municipal de Lençóis Paulista, em conjunto com a Fundação para o Desenvolvimento da UNESP (FUNDUNESP), no sentido de implementar um modelo de gestão que utilizasse a tecnologia ERP e possibilitasse a modernização dos serviços públicos prestados aos cidadãos, bem como a integração e melhor utilização dos recursos.

\section{Sistemas Enterprise Resource Planning (ERP)}

Um sistema ERP tem a pretensão de suportar todas as necessidades de informação para a tomada de decisão gerencial de um empreendimento como um todo. A tradução de Enterprise Resource Planning pode significar "Planejamento de Recursos da Empresa", como resultado de um estágio mais avançado dos sistemas MRP (Material Requirements Planning - Planejamento das Necessidades de Materiais).

O sistema MRP original data dos anos 60, e permite que as empresas calculem quantos materiais de determinado tipo são necessários e em que momento. Para fazer isso, ele utiliza os pedidos em carteira, e/ou uma previsão para as vendas que a empresa acha que irá fazer. O MRP verifica então, todos os ingredientes ou componentes que são necessários para completar os pedidos, garantindo que sejam providenciados a tempo (SLACK et. al., 1997). A Figura 1 mostra o papel do MRP na conciliação do fornecimento e da demanda de recursos.

Conforme Campos (1995), o princípio básico do MRP é o cálculo de necessidades, uma técnica de gestão que permite o cálculo, viabilizado pelo uso de computador, das quantidades e dos momentos em que são necessários os recursos da manufatura (materiais, pessoas e equipamentos, entre outros) para que se cumpram os programas de entrega de produtos, com um mínimo de formação de estoques. Até os anos 60, as empresas sempre tiveram que executar esses cálculos 
manualmente, de modo a garantir que teriam disponíveis os materiais certos nos momentos necessários. Entretanto, com o advento dos computadores e a ampliação de seu uso nas empresas a partir dos anos 60, surgiu a oportunidade de se executarem esses cálculos detalhados e demorados com o auxílio de um computador, de forma rápida e relativamente fácil (SLACK et. al., 1997).

Figura 1 - Uma definição de MRP

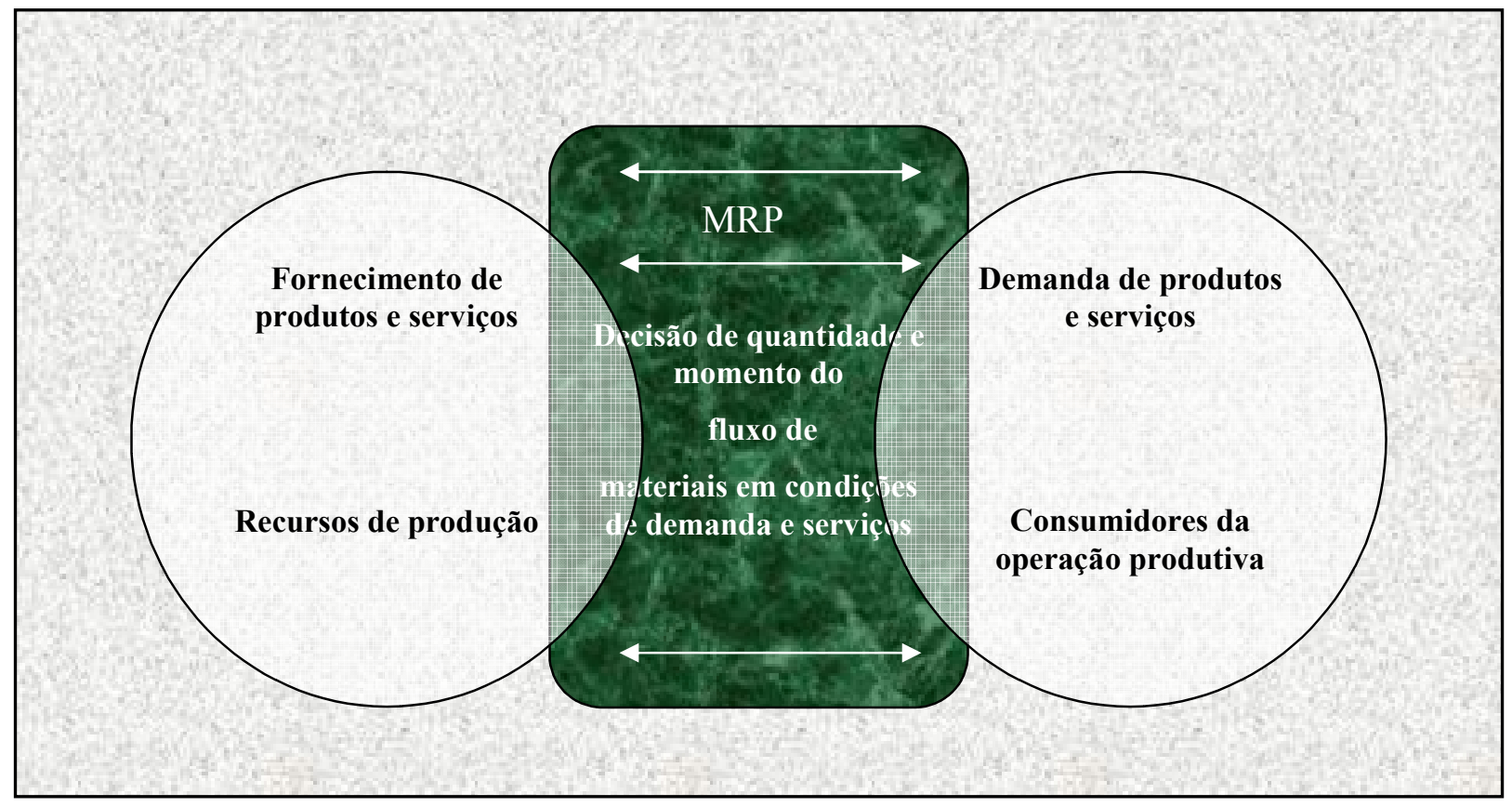

Fonte: Adaptado de Slack et. al., 1997

Segundo Corrêa et. al. (2001), o conceito de cálculo de necessidade de materiais é simples e conhecido há muito tempo. Baseando-se na idéia de que, conhecidos todos os componentes de determinado produto e os tempos de obtenção de cada um deles, pode-se, com base na visão de futuro das necessidades do produto, calcular os momentos e as quantidades que devem ser obtidas de cada um dos componentes para que não haja falta nem sobra de nenhum deles no suprimento das necessidades dadas pela produção do referido produto.

Posteriormente, na década de 70, esse sistema que executava apenas uma das atividades, evoluiu paralelamente ao desenvolvimento da informática, surgindo um sistema computacional com o objetivo de realizar todas as principais tarefas do Planejamento e Controle da Produção (PCP). Por isso o MRP II (Manufacturing Resource Planning - Planejamento dos Recursos da Manufatura) pode ser definido como um sistema abrangendo toda a manufatura (PIRES, 1995). Esse conceito estendido foi denominado MRP II por Oliver Wight, um dos pais do MRP. Wight definiu MRP II como (SLACK et. al., 1997): "Um plano global para o planejamento e monitoramento de todos os recursos de uma empresa de manufatura: manufatura, marketing, finanças e engenharia. Tecnicamente, ele envolve a utilização do sistema MRP de ciclo fechado para gerar números 
financeiros".

Como foi visto anteriormente, o objetivo do MRP é ajudar a produzir e comprar apenas o necessário e apenas no momento necessário (no último momento possível), visando eliminar estoques. Assim qualquer atraso na produção dos itens planejados, irá gerar conseqüências indesejáveis como atraso na produção e na entrega do produto.

O MRP II diferencia-se do MRP pelo tipo de decisão de planejamento que orienta. Enquanto MRP orienta as decisões de o que, quanto e quando produzir e comprar, o MRP II engloba também as decisões referentes a como produzir, ou seja, que recursos utilizar (CORRÊA et. al., 2001).

O MRP II é um sistema com grande capacidade de atuar no nível de planejamento. Essa capacidade de atuar como um sistema integrado de informações torna-o uma importante ferramenta no planejamento em qualquer indústria. A programação tende a ser prejudicada por trabalhar com o conceito de capacidade infinita nos centros produtivos e a necessidade de se conhecer antecipadamente todos os ciclos produtivos dos itens produzidos. Outra dificuldade está no nível de controle, cuja ação é dificultada pelo volume e detalhamento das informações exigidas (PIRES, 1995).

Segundo Pires (1995), até a metade da década de 80 o MRP II era muito mais elogiado do que criticado. Algumas de suas contribuições como o conceito de demanda dependente, controles on line e gerenciamento integrado da produção através de bancos de dados compartilhados, dentre outras, representaram um grande progresso para o PCP.

Com o advento do sistema JIT (Just in Time), o gigantismo dos sistemas MRP II veio à tona, começando a surgir uma série de restrições que perduram até os dias atuais. As críticas mais comuns dizem respeito ao volume de dados planejados/controlados, ao nível de acuracidade exigidos dos mesmos e ao fato de o sistema assumir capacidade infinita em todos os centros produtivos.

O escopo de atuação dos sistemas ERP supera em muito a atuação dos sistemas MRP II. As empresas podem optar por iniciar a implantação dos ERP's por outros módulos que não necessariamente sejam os de manufatura, mas pelos módulos administrativo-financeiros, por exemplo. Uma das vantagens adicionais que os sistemas ERP vieram representar, e que hoje talvez seja a principal motivação de grande número de empresas que optam por adotá-lo, é a integração entre as várias áreas e setores funcionais da organização, todos compartilhando uma mesma base de dados única e não redundante (CORRÊA et. al., 2001). Uma visão geral da abrangência dos sistemas ERP pode ser visto na Figura 2.

Mesmo os ERP's mais desenvolvidos ainda não podem garantir que todos os seus módulos sejam melhores e mais adequados que todos os sistemas atualmente em operação. Às vezes, um determinado sistema, cheio de particularidades, que levou anos de evoluções e aperfeiçoamentos, 
não deveria ser substituído de imediato por outro "padronizado", ou a ser customizado. Muitos ERP's são vários sistemas com interfaces entre si; se uma interface entre dois sistemas diferentes puder se tornar transparente, o problema não existirá.

Figura 2 - Nível de abrangência dos sistemas de produção

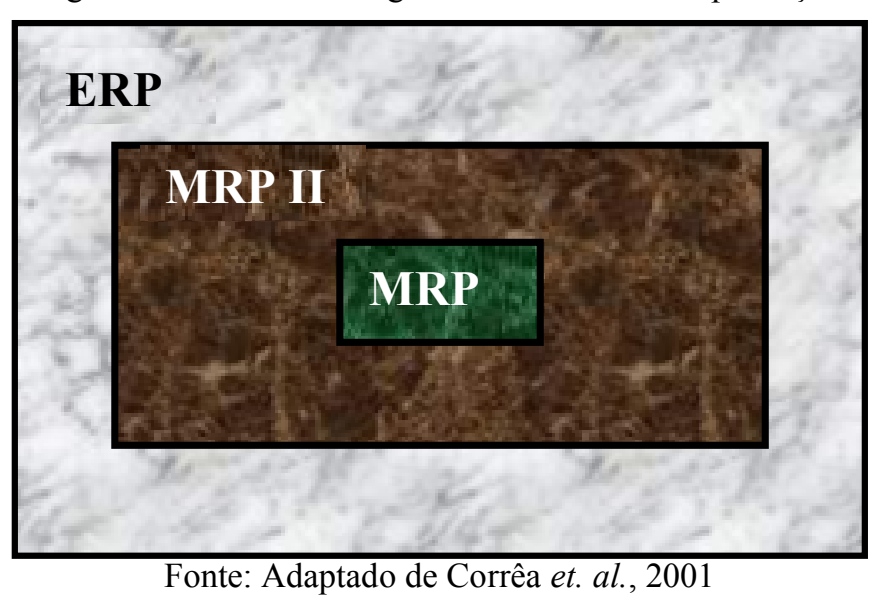

É basicamente composto de módulos que atendem as necessidades de informação para apoio à tomada de decisão de setores que vão além da manufatura, como distribuição física, custos, recebimento fiscal, faturamento, recursos humanos, finanças e contabilidade, dentre outros. Todos esses setores estão integrados entre si e com a manufatura, a partir de uma base de dados única e não redundante.

Segundo Corrêa et. al. (2001), os ERP's costumam apresentar os seguintes módulos:

- Módulos relacionados a operações e Supply Chain Management (SCM) são: Previsões / Análises de Vendas; Lista de Materiais; Programa Mestre de Produção; Planejamento das Necessidades de Materiais - MRP; Planejamento da Capacidade; Compras; Controle de Chão de Fábrica; Controle de Estoques; Engenharia; Distribuição Física; Gerenciamento de Transporte; Gerenciamento de Projetos; Apoio à Produção Repetitiva; Apoio à Gestão de Produção em Processos; Apoio à Programação com Capacidade Finita de Produção Discreta; Configuração de Produtos;

- Módulos relacionados à gestão financeira / contábil / fiscal são: Contabilidade Geral; Custos; Contas a Pagar; Contas a Receber; Faturamento; Recebimento Fiscal; Contabilidade Fiscal; Gestão de Caixa; Gestão de Ativos; Gestão de Pedidos e Gestão dos Processos de Negócio. Pessoal e Folha de Pagamento estão inclusos no módulo relacionado à Gestão de Recursos Humanos.

O conjunto de soluções ERP para o setor público permite automatizar, dinamizar e integrar processos complexos, incluindo (SAP, 2007):

- Contabilidade - Controle da Contabilidade Orçamental, Patrimonial e Analítica dos 
Organismos Públicos bem como gerenciar ciclos de vida de orçamentos, desde a respectiva elaboração e preparação até à execução;

- Gestão do Capital Humano - Integrar processos e informações sobre funcionários com prioridades e estratégias organizacionais;

- Gestão de Aprovisionamento - Permitir efetuar compras e requisições eletrônicas e automatizar processos de orçamentação e contratuais com funcionalidades de conformidade jurídica;

- Gestão da Dívida e Receita Tributária - Realizar a manutenção de contas e registros, otimizar o processamento de declarações e pagamentos, correspondência, faturamento, auditorias e conformidade, bem como apoio ao cidadão e gestão de contestações;

- Gestão de subsistemas de Proteção Social - Dinamizar a gestão de casos específicos e a prestação de um vasto leque de serviços a cidadãos;

- Soluções para e-Government - Aumentar a eficácia e a transparência de processos de forma a corresponder às expectativas dos cidadãos e outros destinatários dos serviços governamentais;

- Serviços de Proteção ao Cidadão - Consolidar dados, partilhar informações e garantir que os recursos estão disponíveis para suportar processos críticos de segurança.

\section{Abordagem Metodológica}

A metodologia de pesquisa adotada depende diretamente do objeto em estudo, de sua natureza, da amplitude e dos objetivos do pesquisador. Pelo método se obtêm soluções ou respostas ao problema ou questão da pesquisa.

Para os levantamentos de campo e análise dos resultados, foi usada a abordagem metodológica de pesquisa qualitativa. Entre as principais técnicas de pesquisa em função do método não-experimental (MARCONI; LAKATOS, 2003) estão a análise de dados existentes, a pesquisa bibliográfica, a análise de conteúdo, a observação, os surveys e o estudo de caso. Cada método de pesquisa possui características próprias que o tornam adequado ou não para responder à pergunta do estudo.

Segundo Yin (2001), cada uma dessas estratégias pode ser usada para os propósitos a seguir, que determinarão como o estudo de caso será: exploratório; descritivo ou explanatório (causal). O Estudo de Caso é preferido quando as questões da pesquisa são da forma "como" e "porque"; quando o controle que o investigador tem sobre os eventos é muito reduzido; ou quando o foco temporal está em fenômenos contemporâneos dentro do contexto de vida real.

A análise das condições relevantes para a estratégia de pesquisa proposta por Yin (2001) 
indica para o emprego do método do estudo de caso exploratório como opção mais adequada à pesquisa. A necessidade de utilizar à estratégia de pesquisa "Estudo de Caso" é dirigida pela busca de entendimento de um fenômeno social complexo.

Foi desenvolvido um protocolo de pesquisa para garantir a confiabilidade da pesquisa. Trata-se de um questionário não estruturado baseado na literatura que serviu de roteiro para os levantamentos. Foram utilizadas, também, várias fontes de dados como jornais, documentos e relatórios.

\section{Estudo de Caso: Implantação de ERP na Prefeitura Municipal de Lençóis Paulista (SP)}

A cidade de Lençóis Paulista, localizada no interior de São Paulo, conta com aproximadamente 62.500 habitantes (dados de 2006) e $808 \mathrm{~km}^{2}$ de área total. Na área da saúde, o município possui um Hospital filantrópico, Pronto Socorro Municipal e vários Postos de Saúde da Família (PSF) distribuídos nos bairros da cidade. Na área da educação, são várias unidades educacionais que a prefeitura administra, desde o maternal (creches), passando pelo ensino básico até o nível universitário. $\mathrm{Na}$ área de saneamento ambiental, a produção e distribuição de água e coleta e tratamento de esgotos são realizados por uma autarquia municipal, e a coleta de resíduos sólidos e drenagem urbana são realizadas por diretorias específicas da administração direta.

Para administrar todo esse volume de recursos e demandas e atender a todas as necessidades do município e de seus moradores, a Prefeitura Municipal conta com um contingente de aproximadamente 1.200 servidores públicos e uma frota de aproximadamente 180 veículos e equipamentos. As administrações das diversas diretorias estão alocadas, além do Paço Municipal, em vários imóveis espalhados pela cidade, alguns próprios e outros locados.

\subsection{A situação da prefeitura no início da atual administração}

A atual administração foi reeleita no último processo eletivo ocorrido em 2004. A situação que a atual administração encontrou nas áreas tributária, de saúde, de educação e de Tecnologia de Informação no início do primeiro mandato (em 2001) foi a seguinte:

a) Gestão Tributária: Cadastro físico-territorial desatualizado; Planta Genérica de Valores defasada; Ausência de fiscalização e treinamento do pessoal em legislação e atendimento; Falta de sistema que permitisse o acompanhamento e cruzamento de informações na área de tributação e ausência de cobrança sistemática de tributos em atraso e dívida ativa;

b) Gestão da Saúde: Falta de informações de atendimento ambulatorial; Ausência de 
integração entre as informações das Unidades Básicas de Saúde; Inexistência de controle de agendamento de consultas / procedimentos médicos; Ausência de controle de dispensação de medicamentos e exames; Fichas (prontuários) de pacientes preenchidas manualmente e dispersas e/ou duplicadas pelas Unidades Básicas de Saúde; Informações ao SUS - Sistema Único de Saúde gerada através de diversas fontes, ocasionando informações divergentes e/ou errôneas; Ausência de informações para a gestão da Saúde no Município;

c) Gestão da Educação; Inexistência de controle informatizado da administração escolar (prontuários, históricos escolares etc.); Processos lentos e burocráticos para transferência de alunos; Ausência de informações para a gestão da Educação no Município;

d) Tecnologia de Informação: Equipamentos de informática insuficientes e defasados em todas as áreas; Rede de computadores ineficiente; Softwares desintegrados gerando informações conflitantes e redundantes; Inexistência de programas de treinamento e desenvolvimento de pessoal.

Optou-se em desenvolver um projeto baseado no conceito de sistemas ERP adaptando-o à administração pública. Com base neste projeto, definiram-se as seguintes diretrizes estratégicas:

- Eficiência, eficácia e transparência das ações do governo (reforma administrativa);

- Recuperação da capacidade de investimento do município;

- Excelência nos serviços prestados à população;

- Busca de respostas à demanda social crescente.

Sendo assim o projeto todo desenvolvido sobre três aspectos básicos: Infra-estrutura de tecnologia da informação, sistema de informação integrado e compartilhado entre todas as diretorias e áreas da administração municipal direta e indireta (autarquias) e capacitação dos servidores públicos municipais.

\subsection{O projeto de implantação de um ERP}

A Prefeitura Municipal de Lençóis Paulista vem, desde 2003, desenvolvendo e implementando um sistema de ERP na administração municipal direta e suas autarquias. Esse projeto envolve todas as Diretorias municipais e está baseado na utilização de um sistema integrado de informações chamado PROGRAM - Programa de Apoio à Governança Municipal.

O sistema PROGRAM foi desenvolvido no curso de Administração Pública da Faculdade de Ciências e Letras - Unesp Araraquara e patenteado pela Fundação para o Desenvolvimento da UNESP (FUNDUNESP) que também registrou a marca Governança Municipal. Foi adotado como premissa para o projeto o conceito tradicional de governança - dar continuidade à administração de 
melhorar sua arrecadação própria e sua forma de gastar recursos acrescentando-se o conceito de transparência na gestão. O conceito de governança adotado está suportado por três elementos: Gestão da informação, Gestão do conhecimento e transparência e fortalecimento das lideranças. (PENZ, 2006)

O projeto de implantação do sistema PROGRAM na Prefeitura de Lençóis Paulista, teve, inicialmente, os seguintes objetivos:

- Integrar, através de modernas ferramentas de informática e comunicação, os diversos setores da Prefeitura Municipal, visando evitar a redundância de informações;

- Aumentar a produtividade na realização das tarefas;

- Recuperar a capacidade de investimento do município através da racionalização dos gastos e aumento da eficiência de arrecadação;

- Estabelecer um relacionamento direto com os cidadãos, através da disponibilização remota de informações.

\subsection{As fases de desenvolvimento do projeto}

Nas etapas iniciais do Projeto foram desenvolvidas algumas atividades para organizar o processo de trabalho e apresentá-lo à comunidade, com a finalidade de garantir ações integradas, interesse, apoio e participação de toda sociedade - fase de divulgação e organização do processo de trabalho.

O projeto foi iniciado pelas seguintes etapas: elaboração de projeto de rede estruturada de comunicação; elaboração de plano de diretrizes para a informática; implantação da infra-estrutura física de redes de computadores e de comunicação; desenvolvimento de competências nos servidores municipais; aquisição de equipamentos de apoio à fisscalização (veículos/motocicletas) e reestruturação da Central de Atendimento ao Contribuinte; aquisição e instalação de equipamentos de informática e comunicação (rádios, servidores, microcomputadores e impressoras).

O sistema de informações está baseado em cadastro multi-finalitário geo-referenciado, tendo sido implementados inicialmente os seguintes cadastros: cadastro físico-territorial, que contém a identificação dos logradouros, imóveis, terrenos etc.; cadastro social, onde consta a identificação dos moradores de cada um dos imóveis; e por fim o cadastro econômico, onde são identificadas as indústrias, comércio e prestadores de serviços. Outros cadastros estão previstos tais como, água e esgoto - redes e ligações, redes de drenagem e outros.

A utilização desses cadastros permitiu a implantação dos seguintes sistemas integrados de gestão de informações e de operações: Gestão da saúde - prontuários centralizados, central de agendamento de consultas entre outros; Gestão da educação - informatização das atividades de 
secretaria das unidades escolares etc.; Gestão da assistência social - cadastramento das famílias e habitantes assistidos etc..

Os recursos para o projeto foram obtidos junto ao BNDES - Banco Nacional de Desenvolvimento, através de uma linha de crédito destinada à modernização da administração pública municipal denominada PMAT - Programa de Modernização da Administração Tributária e Gestão dos Setores Sociais Básicos, no valor de R\$1.100.000,00, conforme tabela 1.

Tabela 1: Distribuição dos recursos do PMAT

\begin{tabular}{|l|r|}
\hline Tecnologia da informação e equipamentos de informática & $\mathrm{R} \$ 385.000,00$ \\
\hline Capacitação de recursos humanos & $\mathrm{R} \$ 200.000,00$ \\
\hline Serviços técnicos especializados & $\mathrm{R} \$ 260.000,00$ \\
\hline Equipamentos de apoio à fiscalização & $\mathrm{R} \$ 30.000,00$ \\
\hline Infra-estrutura física de telecomunicação & $\mathrm{R} \$ 225.000,00$ \\
\hline Total & $\mathbf{R} \$ \mathbf{1 . 1 0 0 , 0 0 0 , 0 0}$ \\
\hline
\end{tabular}

Fonte: Prefeitura Municipal de Lençóis Paulista/SP

\subsection{As dificuldades encontradas}

$\mathrm{Na}$ implementação do projeto foram identificadas várias dificuldades, normalmente encontradas em implementações deste tipo, sendo que as principais delas estavam relacionadas às pessoas, tais como: motivação do quadro de servidores a aceitarem a nova postura da administração; convencimento das pessoas a abandonarem os sistemas de controle antigos, para utilizarem um sistema integrado que, a princípio, exige que as diversas unidades estejam funcionando corretamente para não prejudicar as demais; adaptação das pessoas às novas tecnologias e sistemas de trabalho.

Com relação à tecnologia da informação as dificuldades foram relacionadas à migração das informações dos sistemas antigos, com formato e estrutura de dados diferentes; e a utilização de softwares livres, em especial, os softwares de automação de escritórios, pois as versões livres são diferentes, e em alguns casos, mais limitadas que as versões comerciais. A adaptação dos novos sistemas a determinadas características específicas da Prefeitura Municipal, também foi um fator gerador de dificuldades. Além disso, houve a necessidade de readaptação das estruturas físicas (elétrica e lógica) dos diversos pontos de utilização da rede.

\subsection{Situação do projeto em 2006}

Até dezembro de 2006, já haviam sido implementados diversos sistemas de software e hardware. Da mesma forma, diversos colaboradores da prefeitura foram capacitados para trabalhar no sistema ERP. Na estrutura física, foi formada uma rede metropolitana de informações integrando 36 unidades remotas, por meio de rádio-frequência. Foram distribuídos pelas diversas unidades 8 
servidores de rede e 123 micro-computadores. Foi montada uma Central de Atendimento ao Contribuinte com toda a estrutura de mobiliário e equipamentos de informática disponíveis para atendimento ao contribuinte.

O sistema PROGRAM com arquitetura de ERP, foi desenvolvido em parceria com a FUNDUNESP, envolvendo o controle integrado das áreas de Saúde, Educação, Assistência Social e Cadastro Imobiliário (assentado em uma base cartográfica geo-processada). Para que os sistemas pudessem ser utilizados em sua plenitude foi necessária a realização de cursos de informática para capacitação de cerca de 450 colaboradores municipais. Uma característica inovadora do projeto foi a implantação de software livre. Nos sistemas operacionais de rede foi utilizado o Linux (Fedora). Trata-se de um sistema freeware de arquitetura aberta, o que veio reduzir os custos operacionais da manutenção de sistema operacional. Para automação de escritório utilizou-se o OpenOffice.

As próximas etapas de desenvolvimento do projeto prevêem a implantação de um projeto de ensino a distância para capacitação dos servidores municipais, utilizando o software livre Moodle e implantação de um sistema gerenciador de banco de dados chamado PostgreeSQL. Finalizando com a implantação de um sistema de VoIP (voz sobre IP) e Integração das autarquias municipais com o Cadastro multi-finalitário.

Foram investidos de abril de 2004 (início do projeto) a novembro de 2006 cerca de R\$ 770.000,00. Um valor muito abaixo do que seria gasto se não tivessem sido utilizados softwares livres.

\subsection{Análise dos resultados}

As ações implementadas até o ano de 2006 proporcionaram, entre outras coisas, a redução de custos e aumento de arrecadação do município. Foi gerada uma economia da ordem de R\$ 500.000,00 na aquisição de sistemas operacionais de rede, softwares básicos e aplicativos, tendo em vista a definição de se utilizar software aberto (família Linux e OpenOffice). Houve uma ampliação da arrecadação própria em torno de 43 \% no IPTU - Imposto Predial e Territorial Urbano, e de 95\% no ISSQN - Imposto Sobre Serviços de Qualquer Natureza. Isto foi possível por meio das informações cadastrais atualizadas e mais completas, e melhor fiscalização, entre outras ações.

Foi implantado um cadastro imobiliário atualizado e integrado (chamado também de cadastro multi-finalitário), obtido por meio de mapas digitalizados contendo todas as variáveis de interesse, tais como: ocupação dos imóveis, número e identificação dos habitantes, nível de utilização dos serviços públicos pelos habitantes dos imóveis (saúde, educação, serviço social, lazer e cultura etc.). Além disso, também é utilizado para confirmar o tamanho dos imóveis, facilitar a localização de ruas, quadras, imóveis e proprietários. Possibilita ainda, a visualização espacial de 
variáveis de controle como cadastro de redes de água e esgotos, galerias de drenagem, equipamentos públicos etc. $\mathrm{O}$ cadastro multi-finalitário tem contribuído também em decisões estratégicas de investimento como, por exemplo: em qual bairro deve ser implementado um novo PSF - Posto de Saúde da Família; onde e de que tamanho deve ser implantada uma nova escola etc.

A área da saúde foi uma das grandes beneficiadas pelo projeto. Mediante a interligação de todos os postos de atendimento de saúde (pronto socorro, PSF's, centros de especialidades e laboratórios), houve uma racionalização nos atendimentos, uma vez que o prontuário de cada paciente passou a ser um prontuário único, o qual é acessado e atualizado on-line diretamente do posto de atendimento onde estiver. Outros ganhos sentidos foram a melhor gestão e controle dos estoques de medicamentos disponíveis nas unidades, maior controle sobre as solicitações de exames, maior capacidade de tomada de decisões por parte dos profissionais da saúde e diminuição drástica no tempo de espera para consultas e exames, uma vez que os agendamentos passaram a ser feitos e controlados eletronicamente. $\mathrm{Na}$ área da educação houve maior agilidade na gestão das secretarias escolares com relação a transferência de alunos; controle de freqüência; controle de notas; atribuição de aulas e planejamento escolar.

$\mathrm{Na}$ área social, os ganhos obtidos até o momento estão relacionados à: maior facilidade no controle de programas sociais; apontamento de grupos de risco; acompanhamento das migrações de pessoas e famílias. No relacionamento com o cidadão houve maior transparência das informações, disponibilidade de aceso a $W e b$ e principalmente racionalização dos gastos públicos.

\section{Conclusão}

Dado que o projeto de implantação de um sistema de informações integradas da Prefeitura de Lençóis Paulista ainda está em andamento, algumas conclusões preliminares podem ser levantadas. A implantação do sistema integrado com a utilização de softwares livres permitiu uma redução substancial nos custos de desenvolvimento de um projeto desse porte. Apesar da utilização desses sistemas usualmente mostrar baixa capacidade e pouca facilidade de uso, a escolha mostrouse adequada ao porte e necessidades da prefeitura municipal. A criação de um cadastro multifinalitário permitiu uma visão integrada de informações sociais, econômicas e de tributação, o que permite ações integradas de fiscalização e adoção de políticas públicas, resultando na melhoria da arrecadação, e, conseqüentemente, aumento dos recurso disponíveis para novos investimentos em equipamentos e serviços públicos.

A experiência de Lençóis Paulista e de outros municípios como Américo Brasiliense, Americana e Catanduva, entre outros, onde a iniciativa da implementação do projeto de uso de sistemas ERP para melhorar a administração municipal e torná-la mais transparente e integrada 
partiu das próprias administrações municipais, deu origem a um projeto-piloto denominado Apoio a Governança Municipal, coordenado pelo governo do Estado de São Paulo, por meio da Subsecretaria de Gestão Estratégica, vinculada a Casa Civil, o qual está sendo implementado em um grupo de municípios selecionados com base no potencial econômico, no nível de carência e na localização (MARCO, 2006, p.42).

A utilização de sistemas ERP e outros recursos de tecnologia da informação é um instrumento de transformação da administração pública e principalmente da gestão das cidades, permitindo aos administradores municipais e estaduais tomarem decisões importantes para o município de modo mais rápido e consistente, tendo em vista a disponibilidade de informações em tempo real e integradas entre todas as áreas de abrangência da administração municipal.

\begin{abstract}
The dynamics of growth and development in towns and cities, has brought new obligations to the local governments, as they have started to take responsibilities which in the past belonged to State or Federal governments. This new reality required the application of management models which allowed the local governments to improve both their own tax collection and their way of spending their resources. This paper aims to study how the application of Enterprise Resource Planning(ERP) systems can help the municipal management. For this purpose, a case study of a successful experience of ERP implementation in a local government is presented.
\end{abstract}

Key-words: ERP, public management, governance.

\title{
Referências
}

BRASIL. Lei Federal 10.257, de 10 de julho de 2001. Estatuto da Cidade. Diário Oficial [da] República Federativa do Brasil - Seção 1 - Atos Poder Legislativo Edição no: 133 de 11/07/2001. Disponível em: http://www.cidades.gov.br/images/stories/Lei\%2010\%20257 2001\%20-\%20Estatuto\%20da\%20Cidade.pdf. Acesso em $12 / 01 / 2007$

CAMPOS, D. F. Análise das variáveis mais importantes que afetam o desempenho e a estabilidade dos sistemas MRP. In: ENCONTRO NACIONAL DE ENGENHARIA DE PRODUÇÃO, 15, 1995 São Carlos. Anais. São Paulo: ABEPRO, 1995. v. 3, p. 1441-45.

CORRÊA, H.L, GIANESI, I.G.N, CAON, M. Planejamento, programação e controle da produção: MRP II/ERP: conceitos, uso e implantação. São Paulo: Atlas, $20014^{\mathrm{a} e d .}$

MARCO, S. Suporte Estadual à Governança Municipal. sp.gov revista da Fundação do Desenvolvimento Administrativo - Fundap, São Paulo, Ano 3, n. 8, p. 43-48, 2006.

MARCONI, M. A.; LAKATOS, E. M. Fundamentos de metodologia científica. São Paulo: Atlas, 2003. $5^{\text {a }}$ ed. $311 \mathrm{p}$.

NASCIMENTO, E.R. e DELBUS, I, Entendo a lei de Responsabilidade Fiscal. Brasília: Ministério da Fazenda, 2002 $-2^{\mathrm{a}}$ edição, disponível em http://www.tesouro.fazenda.gov.br /hp/downloads/EntendendoLRF.pdf, acesso em $13 / 01 / 2007$.

PENZ, C. Governança: a cidade transparente como espaço de inclusão. sp.gov revista da Fundação do Desenvolvimento Administrativo - Fundap, São Paulo, Ano 3, n. 8, p. 49, 2006. 
PIRES, S.R.I. Gestão Estratégica da Produção. Piracicaba: Editora Unimep, 1995.

SANTOS, C. M. R. G. Bauru. Eu vivo esta cidade: Projeto Bauru +10 construindo o futuro. Bauru: Editora Senai, 2005 .

SAP PORTUGAL. SAP for Public Sector. Disponível em http://www.sap.com/portugal/ industries/publicsector/businessprocesses/index.epx, acesso em 13/02/2007.

SLACK, N. (org.) Administração da Produção. Revisão técnica Henrique Corrêa e Irineu Gianesi, São Paulo: Atlas, 1997.

YIN, R. K. Estudo de Caso: planejamento e métodos. Porto Alegre: Bookman, 2001. 205p. $2^{\mathrm{a}}$.ed.

KALAKOTA, R \& ROBINSON, M. E-business: estratégias para alcançar o sucesso no mundo digital. 2. ed. Porto Alegre: Bookman, 2002.

\section{Dados completos dos autores:}

José Alexandre Moreno

Faculdade de Engenharia de Bauru / UNESP - Bauru

Departamento de Engenharia da Produção

Mestrando do Curso de Pós Graduação de Engenharia de Produção

R. Cel. Virgilio Rocha, 819 - Lençóis Paulista - SP - Brasil - CEP 18683-371

14-3263.40.63 com. / 14-9772.5423 cel.

jamoreno@feb.unesp.br

\section{José Alcides Gobbo Junior}

Faculdade de Engenharia de Bauru / UNESP - Bauru

Departamento de Engenharia da Produção

Professor doutor

Av. Luiz Edmundo Carrijo Coube, 14-01 Vargem Limpa - Bauru - SP - Brasil - CEP 17033-360

$14-3103.6122$

e-mail:jamoreno@feb.unesp.br

\section{Vagner Cavenaghi}

Faculdade de Engenharia de Bauru / UNESP - Bauru

Departamento de Engenharia da Produção

Professor Doutor

Av. Luiz Edmundo Carrijo Coube, 14-01 Vargem Limpa - Bauru - SP - Brasil - CEP 17033-360

14-3103.6122

jamoreno@feb.unesp.br

Recebido para publicação em: 13/08/07

Aceito para publicação em: 03/09/07 